OPEN ACCESS

Edited by:

Alberto Farolfi,

Romagnolo Scientific Institute for the

Study and Treatment of Tumors

(IRCCS), Italy

Reviewed by:

Dongfeng Zhang,

Qingdao University, China

Tengteng Wang

Brigham and Women's Hospital and Harvard Medical School, United States

*Correspondence:

Xiaolin Yang

xiaolin_yang855@sina.com

Songling Zhang

slzhang@jlu.edu.cn

Specialty section:

This article was submitted to

Women's Cancer,

a section of the journal

Frontiers in Oncology

Received: 24 June 2020 Accepted: 03 November 2020 Published: 01 February 2021

Citation:

Man X, Wang B, Tan Y, Yang X and Zhang S (2021) Aspirin Use and Mortality in Women With Ovarian

Cancer: A Meta-Analysis.

Front. Oncol. 10:575831.

doi: 10.3389/fonc.2020.575831

\section{Aspirin Use and Mortality in Women With Ovarian Cancer: A Meta-Analysis}

\author{
Xiaxia Man ${ }^{1}$, Baogang Wang ${ }^{2}$, Yuying Tan $^{3}$, Xiaolin Yang ${ }^{4 *}$ and Songling Zhang ${ }^{1 *}$ \\ 1 Department of Oncological Gynecology, First Hospital, Jilin University, Changchun, China, ${ }^{2}$ Department of Cardiac Surgery, \\ First Hospital, Jilin University, Changchun, China, ${ }^{3}$ Department of Echocardiography, First Hospital, Jilin University, \\ Changchun, China, ${ }^{4}$ Department of Geriatrics, First Hospital, Jilin University, Changchun, China
}

Background: Aspirin use has been suggested to reduce the incidence of ovarian cancer $(\mathrm{OC})$ in women. However, previous studies regarding the association between aspirin use and mortality in women with OC showed inconsistent results. We aimed to evaluate the association between aspirin use and mortality in women with $\mathrm{OC}$ in a meta-analysis.

Methods: Relevant cohort studies were obtained via search of PubMed, Cochrane's Library, and Embase databases from inception to May 3, 2020. A random-effect model, which incorporates the potential heterogeneity among the included studies, was used to pool the results. Predefined stratified analyses were applied to evaluate the potential study characteristics on the outcome, including the timing of aspirin use, dose of aspirin, age of the women, and the clinical stages of the cancer. Sensitivity analysis by omitting one study at a time was used to assess the stability of the results.

Results: Six cohort studies including 17,981 women with OC were included. Pooled results showed that aspirin use had no statistically significant association with mortality in these patients (adjusted risk ratio [RR]: $0.85,95 \%$ confidence interval [Cl]: 0.70 to 1.02 , $\left.p=0.08 ; 1^{2}=69 \%\right)$. The results were similar for OC-specific mortality (RR: $0.85,95 \% \mathrm{Cl}$ : 0.57 to $1.26, p=0.41$ ) and all-cause mortality (RR: $0.78,95 \% \mathrm{Cl}: 0.55$ to $1.11, p=0.17$ ). Stratified analyses suggested that aspirin use had no statistically significant association with mortality risk in $\mathrm{OC}$ regardless the timing of aspirin use, dose of aspirin, age of the women, or the clinical stages of the cancer. Funnel plots suggested potential risk of publication bias ( $p$ all > 0.05). However, further "trim-and-fill" analysis incorporating hypothesized unpolished studies to achieve symmetrical funnel plots showed similar results of the meta-analysis (RR: $0.91,95 \% \mathrm{Cl}: 0.74$ to $1.13, \mathrm{p}=0.39$ ).

Conclusions: Current evidence from observational studies indicated that aspirin use had no statistically significant association with mortality in women with OC.

Keywords: aspirin, ovarian carcinoma, mortality, cohort studies, meta-analysis 


\section{INTRODUCTION}

Ovarian cancer (OC) is the seventh most commonly diagnosed malignancies and the eighth leading cause of cancer-specific mortality for women all over the world $(1,2)$. Due to the lack of effective screening protocol for early detection of OC on a population level, substantial women with symptoms related with OC are diagnosed at advanced stages $(3,4)$. Accordingly, the overall 5 -year survival for women diagnosed with OC is less than $50 \%$ (5). Therefore, development of strategies to reduce the mortality in women with OC remains of clinical significance $(6,7)$. Accumulating evidence from epidemiological studies suggests that aspirin, one of the most commonly used non-steroidal antiinflammatory drugs (NSAIDs) (8), may have anticancer efficacy (9). Via irreversible inactivation of cyclooxygenase (COX), aspirin is suggested to exert antiplatelet and anti-inflammatory efficacies (8), which have been considered to inhibit the carcinogenesis and metastasis of tumors (10). In addition, observational studies demonstrated that aspirin use is likely to be associated with reduced incidence of many cancers, such as endometrial cancer (11), gastric cancer (12), colorectal and other digestive tract cancers (13), pancreatic cancer (14), hepatocellular carcinoma (15), and OC (16-18). However, uncertainty remains regarding the influence of aspirin use on mortality in women with OC, and previous observational studies evaluating this association showed inconsistent results (19). Some studies suggested that aspirin use was associated with reduced mortality events in women with OC (20-22), while others did not (23-25). In this study, we performed a meta-analysis to systematically evaluate the influence of aspirin use on mortality in women with OC.

\section{METHODS}

The meta-analysis was performed in accordance with the MOOSE (Meta-analysis of Observational Studies in Epidemiology) (26) and Cochrane's Handbook (27) guidelines.

\section{Literature Search}

Studies were identified via systematic search of electronic databases of PubMed Cochrane's Library, and Embase via the following terms: (1) "aspirin" OR "antiplatelet" OR "nonsteroidal anti-inflammatory drugs" OR "NSAIDs"; (2) "ovarian" OR "ovary"; (3) "cancer" OR "carcinoma" OR "tumor" OR "malignancy" OR "neoplasm" and (4) "mortality" OR "death" OR "survival" OR "recurrence" OR "prognosis" OR "progression"). The extensive search strategy was used for database search to avoid missing any possibly related studies. The search was limited to human studies without language restriction. The reference lists of related original and review articles were also analyzed using a manual approach. The final literature search was performed on May 3, 2020.

\section{Study Selection}

The inclusion criteria for the studies were: (1) longitudinal follow-up studies including randomized controlled trials
(RCTs), cohort studies, and nested case-control studies, which were published as full-length articles; (2) women with confirmed diagnosis of OC at baseline were included; (3) association between aspirin use and mortality events during follow-up, including OC-specific mortality and/or all-cause mortality, was evaluated; (4) with a minimal follow-up duration of one year; and (5) reported the relative risk for this association after adjustment of potential confounding factors at least of age. Reviews, editorials, preclinical studies, and studies irrelevant to the aim of current meta-analysis were excluded.

\section{Data Extracting and Quality Evaluation}

Literature search, data extraction, and quality assessment of the included studies were independently performed by two authors according to the predefined criteria. Discrepancies were resolved by consensus or discussion with the corresponding author. Following data were extracted: (1) name of first author, publication year, and country where the study was performed; (2) study design characteristics; (3) patient characteristics, including sample size, age, and clinical stage of OC; (4) definition of aspirin use; (5) follow-up durations; (6) outcomes reported; and (7) confounding factors that were included in the multivariate analyses. The quality of each study was evaluated using the Newcastle-Ottawa Scale (28) which ranges from 1 to 9 stars and judges each study regarding three aspects: selection of the study groups; the comparability of the groups; and the ascertainment of the outcome of interest.

\section{Statistical Analyses}

We used risk ratios (RRs) and their corresponding 95\% confidence intervals (CIs) as the general measure for the association between aspirin use and clinical outcomes. Data of RRs and their corresponding stand errors (SEs) were calculated from $95 \%$ CIs or $\mathrm{p}$ values, and were logarithmically transformed to stabilize variance and normalized the distribution (27). The Cochrane's $\mathrm{Q}$ test and estimation of $\mathrm{I}^{2}$ statistic were used to evaluate the heterogeneity among the include cohort studies (29). A significant heterogeneity was considered if $\mathrm{I}^{2}>50 \%$. We used a random-effect model to synthesize the RR data because this model is considered as a more generalized method which incorporates the potential heterogeneity among the included studies (27). Sensitivity analyses by omitting one individual study at a time were performed to test the robustness of the results (30). Stratified analyses were performed according to the definition of mortality outcome, timing of aspirin use, aspirin dose, age of the women, and the International Federation of Gynecology and Obstetrics (FIGO) stage of OC. The potential publication bias was assessed by funnel plots with the Egger's regression asymmetry test (31). A "trim-and-fill" analysis was performed if publication bias was suggested. By incorporating the imputed unpublished studies, symmetrical funnel plots were generated via this method and the results of pooled analysis including these hypothesized studies were subsequently performed (27). We used the RevMan (Version 5.1; Cochrane Collaboration, Oxford, UK) and STATA software for the metaanalysis and statistics. 


\section{RESULTS}

\section{Literature Search}

The process of database search was summarized in Figure 1. Briefly, 592 articles were found via initial literature search of the PubMed, Cochrane's Library, and Embase databases, and 568 were excluded through screening of the titles and abstracts mainly because they were not relevant to the purpose of the meta-analysis. Subsequently, 24 potential relevant records underwent full-text review. Of these, 18 were further excluded based on reasons listed in Figure 1. Finally, six studies were included (20-25).

\section{Study Characteristics and Quality Evaluation}

The characteristics of the included studies were summarized in Table 1. One study was a pooled analysis of individual-level data from 12 Ovarian Cancer Association Consortium studies (23), four were retrospective cohort studies (20, 22, 24, 25), and the other one was a prospective cohort study (21). Overall, 17,981 women with confirmed diagnosis of OC from Israel, USA, UK, Australia, and Denmark were included in these studies. The sample sizes of the included women varied between 77 and 11,967. The mean age of the included women varied from 53 to 64 years. Four studies included women with FIGO stages I-IV OC (20, 22-24), while the other two studies included women with stages I-III (21) and IIIC-IV (25) OC, respectively. Aspirin users were validated by prescription records in five studies (20-22, 24, 25), and by self-report questionnaires in one study (23). Moreover, post-diagnostic use of aspirin was analyzed for the included studies, except for one study in which prediagnostic use of aspirin was analyzed (23). The follow-up duration varied from 2.1 to 7.8 years. Potential confounding factors, such as age, cancer stages, anticancer treatments, comorbidities, and other concurrent medications, were adjusted in the multivariate analyses of the original studies. The NOS scores of the included studies ranged from six to nine, indicating generally good study quality (Table 2 ).

\section{Meta-Analysis Results}

Pooled results of six studies with a random-effect model showed that aspirin use had no statistically significant association with mortality in these patients (adjusted RR: $0.85,95 \% \mathrm{CI}: 0.70$ to $1.02, \mathrm{p}=0.08$ ) with significant heterogeneity ( $\mathrm{p}$ for Cochrane's $\mathrm{Q}$ test $=0.006, \mathrm{I}^{2}=69 \%$; Figure 2A). Sensitivity analysis by omitting either of the included study did not significantly change the results (RR: 0.76 to $0.90, \mathrm{p}$ all > 0.05; Table 3). Subgroup analysis showed similar results in studies that reported OC-specific mortality (RR: $0.85,95 \% \mathrm{CI}: 0.57$ to $1.26, \mathrm{p}=0.41$ ) and all-cause mortality (RR: $0.78,95 \% \mathrm{CI}$ : 0.55 to $1.11, \mathrm{p}=0.17$; Figure 2B). Further stratified analyses showed that aspirin use had no statistically significant association with mortality in women with OC in studies of aspirin use before (RR: 0.96, 95\% CI: 0.88 to $1.04, \mathrm{p}=0.34$ ) and after the diagnosis of OC

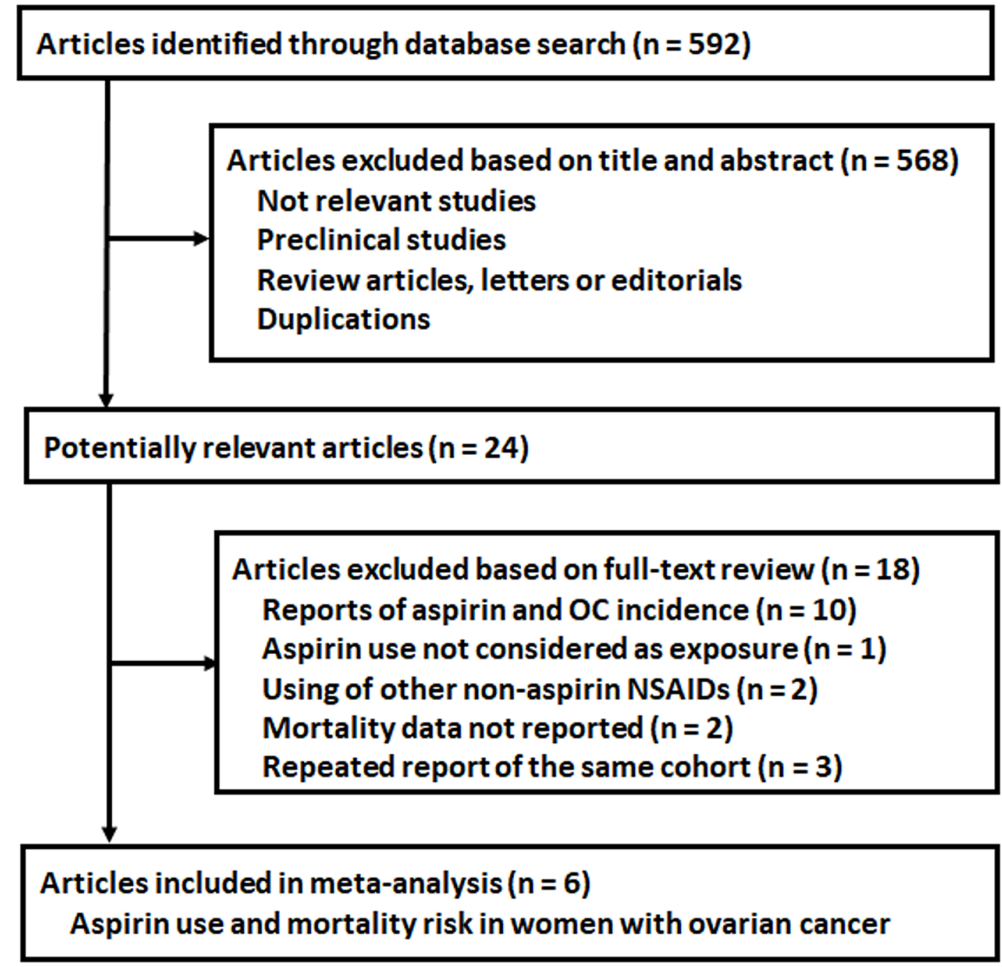

FIGURE 1 | Flowchart of literature search. 
TABLE 1 | Characteristics of the included cohort studies.

\begin{tabular}{|c|c|c|c|c|c|c|c|c|c|c|c|}
\hline Study & Design & Country & $\begin{array}{c}\text { Patient } \\
\text { characteristics }\end{array}$ & $\begin{array}{l}\text { Patient } \\
\text { number }\end{array}$ & $\begin{array}{l}\text { Mean } \\
\text { age }\end{array}$ & $\begin{array}{l}\text { FIGO } \\
\text { stage }\end{array}$ & $\begin{array}{l}\text { Definition } \\
\text { of aspirin } \\
\text { use }\end{array}$ & $\begin{array}{l}\text { Follow- } \\
\text { up } \\
\text { duration }\end{array}$ & $\begin{array}{l}\text { Outcomes } \\
\text { reported }\end{array}$ & $\begin{array}{l}\text { Outcome } \\
\text { validation }\end{array}$ & Variables adjusted \\
\hline & & & & & years & & & years & & & \\
\hline $\begin{array}{l}\text { Bar et al. } \\
(20)\end{array}$ & $\mathrm{RC}$ & Israel & $\begin{array}{l}\text { Women with OC } \\
\text { treated by } \\
\text { debulking } \\
\text { surgery and } \\
\text { platinum based } \\
\text { chemotherapy }\end{array}$ & 143 & 62.5 & I-IV & $\begin{array}{l}\text { Aspirin use } \\
\text { after OC } \\
\text { diagnosis by } \\
\text { pharmacy } \\
\text { records }\end{array}$ & 2.1 & $\begin{array}{l}\text { All-cause } \\
\text { deaths (78) }\end{array}$ & $\begin{array}{l}\text { Medical } \\
\text { database }\end{array}$ & $\begin{array}{l}\text { Age, cancer stage, cancer } \\
\text { treatment, comorbidities, and } \\
\text { concurrent medications }\end{array}$ \\
\hline $\begin{array}{l}\text { Dixon } \\
\text { et al. (23) }\end{array}$ & $\begin{array}{l}\text { Pooled } \\
\text { study } \\
\text { of RC }\end{array}$ & $\begin{array}{l}\text { USA, UK, } \\
\text { Australia, } \\
\text { and } \\
\text { Denmark }\end{array}$ & $\begin{array}{l}\text { Women with } \\
\text { epithelial OC }\end{array}$ & 11967 & 57.0 & I-IV & $\begin{array}{l}\text { Self- } \\
\text { reported } \\
\text { use of } \\
\text { aspirin at } \\
\text { least } 1 / \mathrm{w} \\
\text { before OC } \\
\text { diagnosis }\end{array}$ & 7.3 & $\begin{array}{l}\text { All-cause } \\
\text { deaths } \\
(4,273)\end{array}$ & $\begin{array}{l}\text { National death } \\
\text { index }\end{array}$ & Age, education, and ethnicity \\
\hline $\begin{array}{l}\text { Verdoodt } \\
\text { et al. (24) }\end{array}$ & $\mathrm{RC}$ & Denmark & $\begin{array}{l}\text { Women aged } \\
\text { 30-84 years } \\
\text { with primary } \\
\text { epithelial OC }\end{array}$ & 4117 & 62.5 & I-IV & $\begin{array}{l}\text { Low-dose } \\
\text { aspirin use } \\
\text { after the } \\
\text { diagnosis of } \\
\text { OC }\end{array}$ & 3.6 & $\begin{array}{l}\text { OC-specific } \\
\text { deaths } \\
(2,245)\end{array}$ & $\begin{array}{l}\text { National } \\
\text { demographic, } \\
\text { prescription, } \\
\text { and patient } \\
\text { registries }\end{array}$ & $\begin{array}{l}\text { Age, education, disposable } \\
\text { income, marital status, } \\
\text { comorbid, cancer stage, } \\
\text { histology, chemotherapy, and } \\
\text { non-aspirin drug use }\end{array}$ \\
\hline $\begin{array}{l}\text { Wield } \\
\text { et al. (22) }\end{array}$ & $\mathrm{RC}$ & USA & $\begin{array}{l}\text { Women with } \\
\text { clear cell OC }\end{array}$ & 77 & 53.4 & I-IV & $\begin{array}{l}\text { Aspirin use } \\
\text { after the } \\
\text { diagnosis of } \\
\text { OC }\end{array}$ & 7.8 & $\begin{array}{l}\text { All-cause } \\
\text { deaths (33) }\end{array}$ & $\begin{array}{l}\text { Medical } \\
\text { database }\end{array}$ & $\begin{array}{l}\text { Age, cancer stage and } \\
\text { cytoreductive status }\end{array}$ \\
\hline $\begin{array}{l}\text { Merritt } \\
\text { et al. (21) }\end{array}$ & $\mathrm{PC}$ & USA & $\begin{array}{l}\text { Women with } \\
\text { invasive } \\
\text { epithelial OC }\end{array}$ & 1143 & 63.2 & $|-|||$ & $\begin{array}{l}\text { Aspirin use } \\
\text { after the } \\
\text { diagnosis of } \\
\text { OC within } \\
2 y\end{array}$ & 4.2 & $\begin{array}{l}\text { OC-specific } \\
\text { deaths } \\
(491)\end{array}$ & $\begin{array}{l}\text { Medical } \\
\text { database }\end{array}$ & $\begin{array}{l}\text { Age, cancer stage, histology, } \\
\text { parity, duration of oral } \\
\text { contraceptive use, menopausal } \\
\text { status, family history of OC, } \\
\text { smoking, BMl, and concurrent } \\
\text { medications }\end{array}$ \\
\hline $\begin{array}{l}\text { Gonzalez } \\
\text { et al. (25) }\end{array}$ & $\mathrm{RC}$ & USA & $\begin{array}{l}\text { Women with } \\
\text { stage IIIC-IV } \\
\text { epithelial OC }\end{array}$ & 534 & 64.0 & IIIC-IV & $\begin{array}{l}\text { Aspirin use } \\
\text { after the } \\
\text { diagnosis of } \\
\text { OC }\end{array}$ & 6.2 & $\begin{array}{l}\text { All-cause } \\
\text { deaths } \\
(339)\end{array}$ & $\begin{array}{l}\text { Medical } \\
\text { database }\end{array}$ & $\begin{array}{l}\text { Age, race, age, } \mathrm{CCl} \text {, cancer } \\
\text { stage, triage to neoadjuvant } \\
\text { chemotherapy, histology, } \\
\text { residual disease status, and } \\
\text { concurrent medications }\end{array}$ \\
\hline
\end{tabular}

OC, ovarian cancer; FIGO, International Federation of Gynecology and Obstetrics; NOS, Newcastle-Ottawa Scale; RC, retrospective; PC, prospective; BMI, body mass index; CCI, Charlson Comorbidity Index.

TABLE 2 | Details of study quality evaluation via the Newcastle-Ottawa Scale.

\begin{tabular}{|c|c|c|c|c|c|c|c|c|c|c|}
\hline Study & $\begin{array}{c}\text { Representativeness } \\
\text { of the exposed } \\
\text { cohort }\end{array}$ & $\begin{array}{l}\text { Selection of } \\
\text { the non- } \\
\text { exposed } \\
\text { cohort }\end{array}$ & $\begin{array}{l}\text { Ascertainment } \\
\text { of exposure }\end{array}$ & $\begin{array}{l}\text { Outcome } \\
\text { not present } \\
\text { at baseline }\end{array}$ & $\begin{array}{l}\text { Control } \\
\text { for age } \\
\text { and } \\
\text { gender }\end{array}$ & $\begin{array}{l}\text { Control for } \\
\text { other con- } \\
\text { founding } \\
\text { factors }\end{array}$ & $\begin{array}{l}\text { Assessment } \\
\text { of outcome }\end{array}$ & $\begin{array}{l}\text { Enough } \\
\text { long } \\
\text { follow-up } \\
\text { duration }\end{array}$ & $\begin{array}{l}\text { Adequacy } \\
\text { of follow-up } \\
\text { of cohorts }\end{array}$ & Total \\
\hline $\begin{array}{l}\text { Bar et al. } \\
(20)\end{array}$ & 0 & 1 & 1 & 1 & 1 & 1 & 1 & 0 & 1 & 7 \\
\hline $\begin{array}{l}\text { Dixon } \\
\text { et al. (23) }\end{array}$ & 1 & 1 & 0 & 1 & 1 & 1 & 0 & 1 & 1 & 7 \\
\hline $\begin{array}{l}\text { Verdoodt } \\
\text { et al. (24) }\end{array}$ & 1 & 1 & 1 & 1 & 1 & 1 & 1 & 0 & 1 & 8 \\
\hline $\begin{array}{l}\text { Wield } \\
\text { et al. (22) }\end{array}$ & 0 & 1 & 1 & 1 & 1 & 0 & 0 & 1 & 1 & 6 \\
\hline $\begin{array}{l}\text { Merritt } \\
\text { et al. (21) }\end{array}$ & 1 & 1 & 1 & 1 & 1 & 1 & 1 & 1 & 1 & 9 \\
\hline $\begin{array}{l}\text { Gonzalez } \\
\text { et al. (25) }\end{array}$ & 0 & 1 & 1 & 1 & 1 & 1 & 0 & 1 & 1 & 7 \\
\hline
\end{tabular}

( $R R=0.76,95 \%$ CI: 0.56 to $1.04, p=0.09$; Figure 3A), in studies with aspirin dose $\leq 150 \mathrm{mg} /$ day (RR: $0.96,95 \%$ CI: 0.84 to 1.09 , $\mathrm{p}=0.50)$ and $\geq 325 \mathrm{mg} /$ day $(\mathrm{RR}=0.89,95 \% \mathrm{CI}: 0.72$ to $1.11, \mathrm{p}=$ 0.30 ; Figure 3B), in elderly (RR: $1.11,95 \%$ CI: 0.99 to 1.24 , $\mathrm{p}=0.08)$ and non-elderly women with $\mathrm{OC}(\mathrm{RR}=0.92,95 \%$ CI: 0.81 to $1.04, p=0.17$; Figure $4 \mathrm{~A}$ ), and in women with stages I-II (RR: $0.91,95 \% \mathrm{CI}: 0.69$ to $1.20, \mathrm{p}=0.51$ ) and stages III-IV OC $(\mathrm{RR}=0.94,95 \% \mathrm{CI}: 0.83$ to $1.06, \mathrm{p}=0.31$; Figure $4 \mathrm{~B})$. 


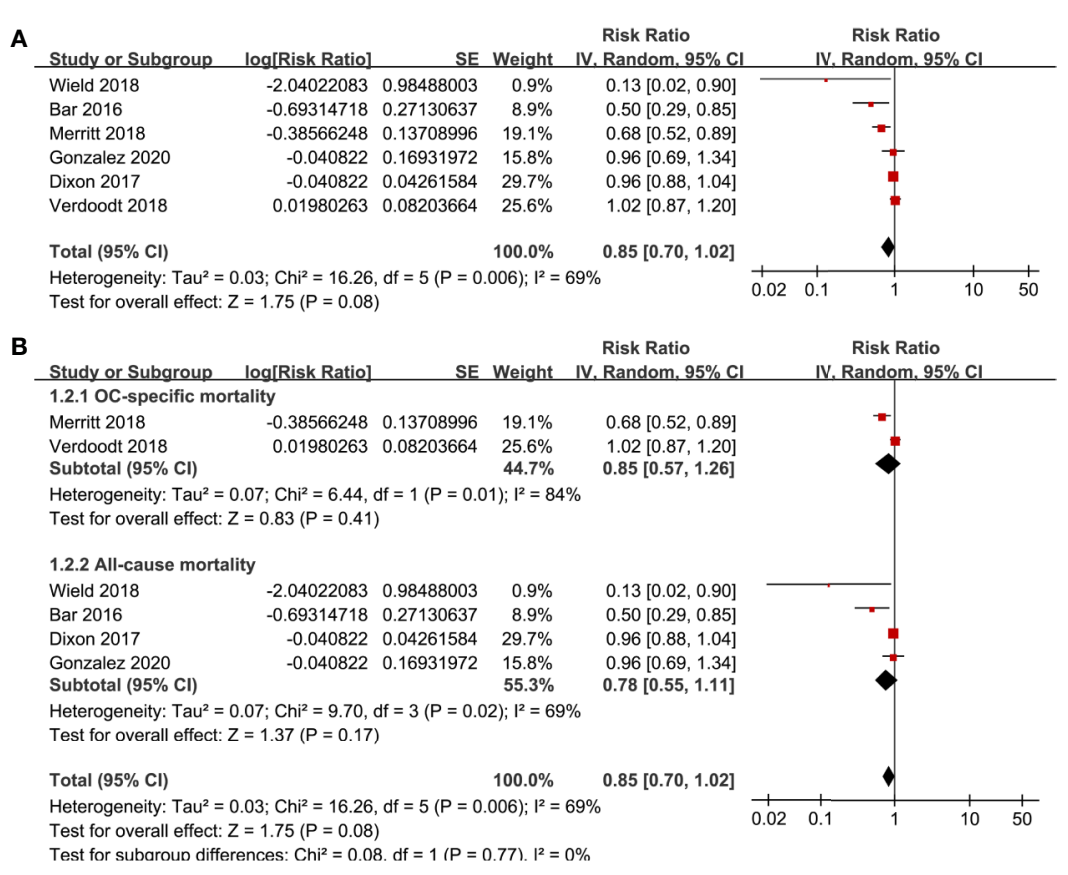

FIGURE 2 | Forest plots for the meta-analysis of the association between aspirin use and mortality risk in women with OC; (A) overall meta-analysis; and (B) subgroup analysis by the definition of mortality outcome.

\section{Publication Bias}

The funnel plots for the meta-analysis of the association between aspirin use and mortality risk in women with OC were shown in Figure 5. The plots were asymmetrical on visual inspection, suggesting potential risks of publication biases. By trim-and-fill analyses, two hypothesized studies were imputed. Meta-analysis incorporating these two studies did not significantly change the results (RR: $0.91,95 \% \mathrm{CI}: 0.74$ to $1.13, \mathrm{p}=0.39$ ).

\section{DISCUSSION}

In this meta-analysis of cohort studies, we found that aspirin use had no statistically significant association with mortality risk in women with OC. Sensitivity analyses by excluding one study at a time did not change the results, indicating that the results of the meta-analysis were stable. Subgroup analyses showed consistent results in studies reporting OC-specific mortality or all-cause mortality. Stratified analyses showed that aspirin use had no statistically significant association with mortality in women with OC regardless the timing of aspirin use, dose of aspirin, age of the women, or the clinical stages of the cancer. Taken together, these results suggested that based on current evidence from epidemiological studies, aspirin use had no statistically significant association with mortality in women with OC.

A previous pooled analysis of individual-level data from 12 Ovarian Cancer Association Consortium studies showed that in women with OC, self-reported pre-diagnostic use of aspirin was not associated with significantly affected all-cause mortality (23). Our meta-analysis based on study-level further confirmed that aspirin use was not associated with significantly affected mortality risk in these patients. Both retrospective and prospective cohort studies were included. Moreover, aspirin use was validated by pharmacy records in five of the included studies $(20-22,24,25)$, which were less biased than self-reported use in questionnaires. Different from the previous pooled-analysis, we performed multiple stratified analyses to evaluate whether the association could be affected by factors such as the timing of aspirin use, dose of aspirin, age of the

TABLE 3 | Results of sensitivity analysis.

\begin{tabular}{|c|c|c|c|c|}
\hline Studies excluded & $\mathbf{R R}$ & $95 \% \mathrm{Cl}$ & $\mathrm{I}^{2}$ & $P$ for effect \\
\hline Baret al. (20) & 0.90 & 0.76 to 1.06 & $63 \%$ & 0.22 \\
\hline Dixon et al. (23) & 0.76 & 0.56 to 1.04 & $74 \%$ & 0.09 \\
\hline Verdoodt et al. (24) & 0.76 & 0.58 to 1.02 & $73 \%$ & 0.07 \\
\hline Wield et al. (22) & 0.87 & 0.73 to 1.03 & $67 \%$ & 0.10 \\
\hline Merritt et al. (21) & 0.90 & 0.75 to 1.09 & $62 \%$ & 0.29 \\
\hline Gonzalez et al. (25) & 0.81 & 0.65 to 1.02 & $75 \%$ & 0.08 \\
\hline
\end{tabular}

$R R$, risk ratio; $\mathrm{Cl}$, confidence interval. 


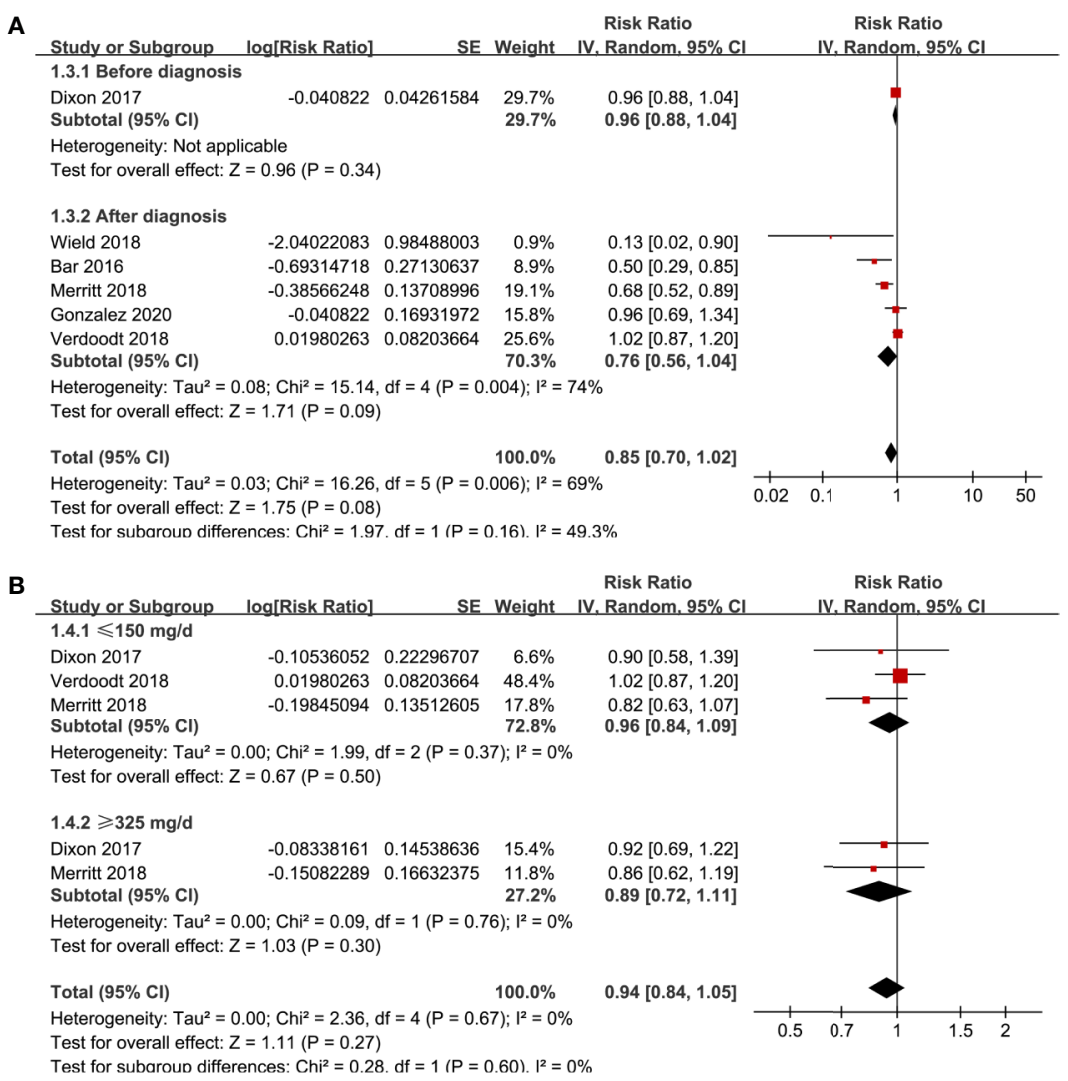

FIGURE 3 | Stratified analyses for the meta-analysis of the association between aspirin use and mortality risk in women with OC; (A) stratified according to the timing of aspirin use; and (B) stratified according to the dose of aspirin.

women, and the clinical stages of the cancer. All of the above stratified analyses showed no significant association between aspirin use and mortality of OC. These findings further confirmed that aspirin use had no statistically significant association with mortality in women with OC.

These findings are contrary to previous preclinical studies, which generally indicated that aspirin confers anticancer efficacy in OC. An early in-vitro study showed that aspirin inhibited ovarian tumor cell growth in a dose-dependent manner (32). Subsequent studies showed that aspirin could inhibit the proliferation of ovarian tumor cells via multiple mechanisms, such as direct inactivation of COX-2 (33) and inhibition of platelet activation (34). Besides, aspirin was shown to exert antiangiogenic effect in mice model of OC, suggesting its inhibitory effect on metastasis of ovarian tumor cells (35). The potential reasons for the discrepancies between the results of meta-analysis and preclinical studies may primarily be attributed to the complexity of the role of aspirin in women with OC than that in tumor cell lines or animal models. The comorbidities and concurrent medications are likely to affect the potential anticancer efficacy of aspirin. Moreover, the possible anticancer efficacy of aspirin may become clinically irrelevant in women who had already received adequate treatments against OC based on current medical recommendation. However, it has to be mentioned that it is somewhat biased to evaluate the potential efficacy of aspirin on survival in OC based on cohort studies. In these studies, aspirin was prescribed for other indications rather than the anticancer purpose. Therefore, those who use aspirin before the diagnosis of the cancer are likely to have other comorbidities which could lead to poor prognosis, thereby masking the potential benefits of aspirin. Moreover, those who have more advanced cancer, and thus a worse prognosis, might be less likely to take aspirin after diagnosis, which may be another reason to confound the results. Considering these potential biases, the efficacy of aspirin on mortality in women with OC should be optimally evaluated in clinical trials.

Our study has limitations. Firstly, studies available for the metaanalysis and stratified analyses were limited. Moreover, since we did not have access to individual-patient data of the included studies, the stratified analyses were performed based on study-level data. The findings should be interpreted with caution. Secondly, significant heterogeneity was found among the included studies. Although stratified analyses did not support that timing of aspirin use, dose of aspirin, age of the women, and the clinical stages of the cancer may contribute to the heterogeneity. We could not exclude other characteristics that may contribute to the heterogeneity, such as the histological subtype of OC and the anticancer treatments applied in each study. Further studies are needed to evaluate the influence of these factors on the outcomes. Finally, as mentioned 
A

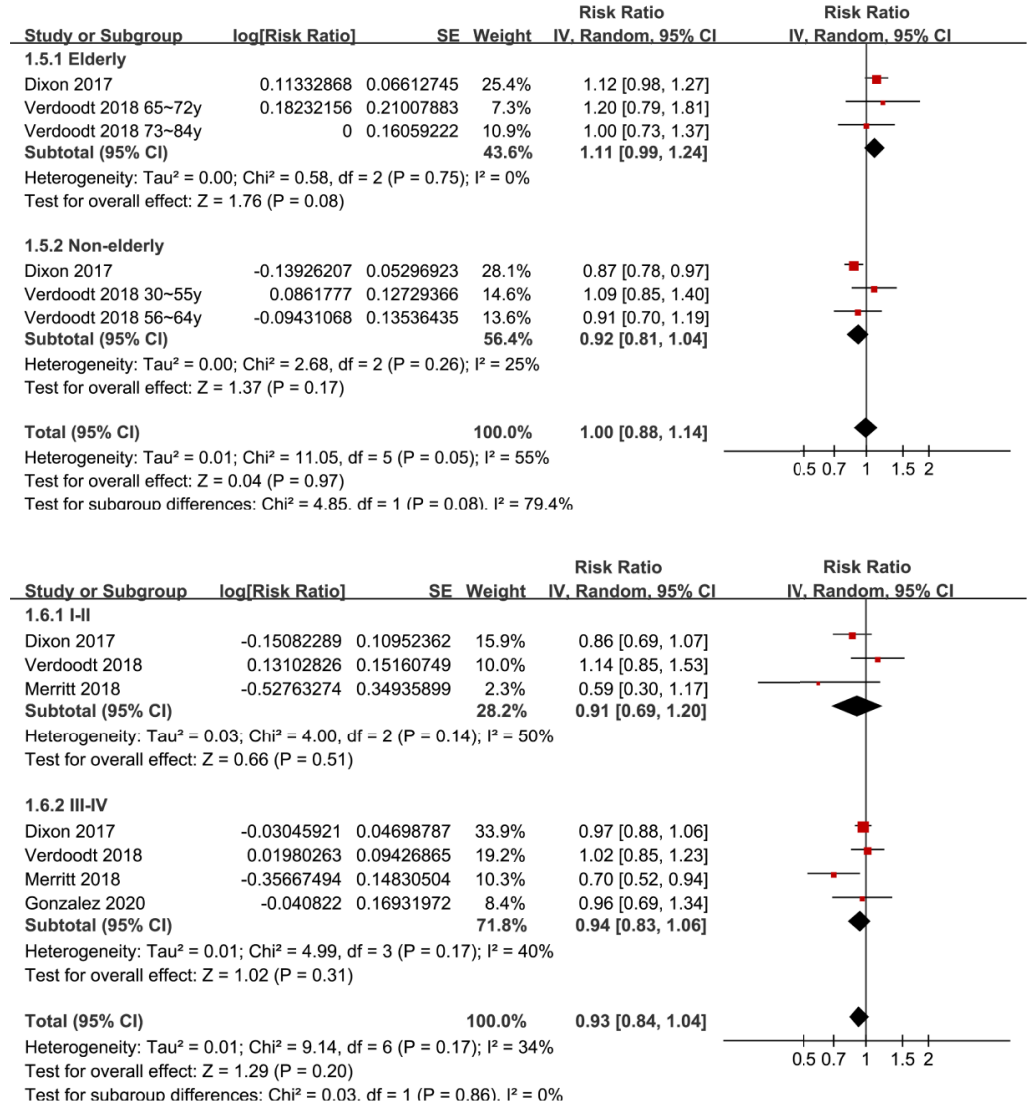

FIGURE 4 | Stratified analyses for the meta-analysis of the association between aspirin use and mortality risk in women with OC; (A) stratified according to the age of the women; and (B) stratified according to the FIGO stage of OC.

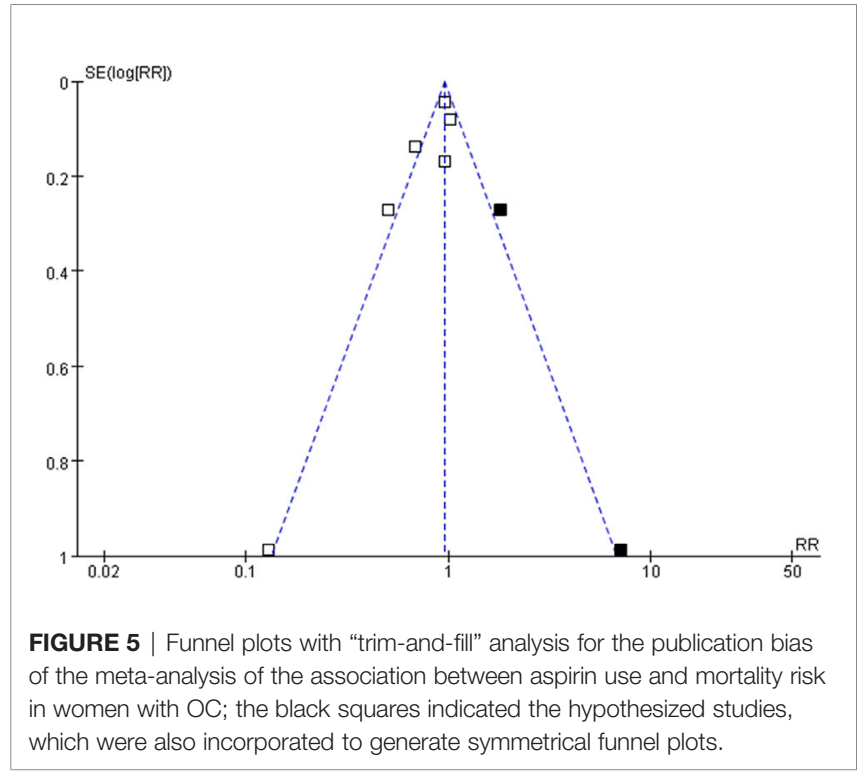

above, due to the inherited biases in observational studies, RCTs are warranted to validate the efficacy of aspirin on mortality in women with OC.
In conclusion, results of the meta-analysis based on evidence from epidemiological studies showed that aspirin use had no statistically significant association with mortality in women with OC. In view of the consistent anticancer efficacy of aspirin observed in the preclinical studies, as well as the potential limitations of observational studies, clinical trials may be considered to investigate the influence of aspirin on mortality in women with OC.

\section{DATA AVAILABILITY STATEMENT}

The original contributions presented in the study are included in the article/supplementary material. Further inquiries can be directed to the corresponding authors.

\section{AUTHOR CONTRIBUTIONS}

$\mathrm{XY}$ and SZ conceived and designed the study. XM and BW selected the studies and collected the data. XM and YT analyzed data. All authors interpreted the results. XM, XY, and SZ drafted the paper. All authors revised the draft paper. All authors contributed to the article and approved the submitted version. 


\section{REFERENCES}

1. Coburn SB, Bray F, Sherman ME, Trabert B. International patterns and trends in ovarian cancer incidence, overall and by histologic subtype. Int J Cancer (2017) 140(11):2451-60. doi: 10.1002/ijc.30676

2. Boussios S, Mikropoulos C, Samartzis E, Karihtala P, Moschetta M, Sheriff M, et al. Wise Management of Ovarian Cancer: On the Cutting Edge. J Pers Med (2020) 10(2):41. doi: 10.3390/jpm10020041

3. Trinidad CV, Tetlow AL, Bantis LE, Godwin AK. Reducing Ovarian Cancer Mortality Through Early Detection: Approaches Using Circulating Biomarkers. Cancer Prev Res (Phila) (2020) 13(3):241-52. doi: 10.1158/ 1940-6207.CAPR-19-0184

4. Nash Z, Menon U. Ovarian cancer screening: Current status and future directions. Best Pract Res Clin Obstet Gynaecol (2020) 65:32-45. doi: 10.1016/ j.bpobgyn.2020.02.010

5. Chandra A, Pius C, Nabeel M, Nair M, Vishwanatha JK, Ahmad S, et al. Ovarian cancer: Current status and strategies for improving therapeutic outcomes. Cancer Med (2019) 8(16):7018-31. doi: 10.1002/cam4.2560

6. Lee JM, Minasian L, Kohn EC. New strategies in ovarian cancer treatment. Cancer (2019) 125 Suppl 24:4623-9. doi: 10.1002/cncr.32544

7. Glajzer J, Grabowski JP, Sehouli J, Pfisterer J. Recurrent Treatment in Ovarian Cancer Patients: What Are the Best Regimens and the Order They Should Be Given? Curr Treat Options Oncol (2020) 21(6):49. doi: 10.1007/s11864-02000747-7

8. Michiels JJ. Platelet-mediated microvascular inflammation and thrombosis in thrombocythemia vera: a distinct aspirin-responsive arterial thrombophilia, which transforms into a bleeding diathesis at increasing platelet counts. Pathol Biol (Paris) (2003) 51(3):167-75. doi: 10.1016/S0369-8114(03)00038-5

9. Hua H, Zhang H, Kong Q, Wang J, Jiang Y. Complex roles of the old drug aspirin in cancer chemoprevention and therapy. Med Res Rev (2019) 39 (1):114-45. doi: 10.1002/med.21514

10. Palacios-Acedo AL, Mege D, Crescence L, Dignat-George F, Dubois C, Panicot-Dubois L. Platelets, Thrombo-Inflammation, and Cancer: Collaborating With the Enemy. Front Immunol (2019) 10:1805. doi: 10.3389/fimmu.2019.01805

11. Wang Y, Zhao J, Chen X, Zhang F, Li X. Aspirin use and endometrial cancer risk: a meta-analysis and systematic review. Ann Transl Med (2020) 8(7):461. doi: $10.21037 /$ atm.2020.03.125

12. Niikura R, Hirata Y, Hayakawa Y, Kawahara T, Yamada A, Koike K. Effect of aspirin use on gastric cancer incidence and survival: A systematic review and meta-analysis. JGH Open (2020) 4(2):117-25. doi: 10.1002/jgh3.12226

13. Bosetti C, Santucci C, Gallus S, Martinetti M, La Vecchia C. Aspirin and the risk of colorectal and other digestive tract cancers: an updated meta-analysis through 2019. Ann Oncol (2020) 31(5):558-68. doi: 10.1016/j.annonc.2020.02.012

14. Sun J, Li Y, Liu L, Jiang Z, Liu G. Aspirin use and pancreatic cancer risk: A systematic review of observational studies. Medicine (Baltimore) (2019) 98 (51):e18033. doi: 10.1097/MD.0000000000018033

15. Wang S, Yu Y, Ryan PM, Dang M, Clark C, Kontogiannis V, et al. Association of aspirin therapy with risk of hepatocellular carcinoma: A systematic review and dose-response analysis of cohort studies with 2.5 million participants. Pharmacol Res (2020) 151:104585. doi: 10.1016/j.phrs.2019.104585

16. Trabert B, Ness RB, Lo-Ciganic WH, Murphy MA, Goode EL, Poole EM, et al. Aspirin, nonaspirin nonsteroidal anti-inflammatory drug, and acetaminophen use and risk of invasive epithelial ovarian cancer: a pooled analysis in the Ovarian Cancer Association Consortium. J Natl Cancer Inst (2014) 106(2): djt431. doi: 10.1093/jnci/djt431

17. Zhang D, Bai B, Xi Y, Wang T, Zhao Y. Is aspirin use associated with a decreased risk of ovarian cancer? A systematic review and meta-analysis of observational studies with dose-response analysis. Gynecol Oncol (2016) 142 (2):368-77. doi: 10.1016/j.ygyno.2016.04.543

18. Qiao Y, Yang T, Gan Y, Li W, Wang C, Gong Y, et al. Associations between aspirin use and the risk of cancers: a meta-analysis of observational studies. BMC Cancer (2018) 18(1):288. doi: 10.1186/s12885-018-4156-5

19. Verdoodt F, Kjaer SK, Friis S. Influence of aspirin and non-aspirin NSAID use on ovarian and endometrial cancer: Summary of epidemiologic evidence of cancer risk and prognosis. Maturitas (2017) 100:1-7. doi: 10.1016/ j.maturitas.2017.03.001
20. Bar D, Lavie O, Stein N, Feferkorn I, Shai A. The effect of metabolic comorbidities and commonly used drugs on the prognosis of patients with ovarian cancer. Eur J Obstet Gynecol Reprod Biol (2016) 207:227-31. doi: 10.1016/j.ejogrb.2016.09.005

21. Merritt MA, Rice MS, Barnard ME, Hankinson SE, Matulonis UA, Poole EM, et al. Pre-diagnosis and post-diagnosis use of common analgesics and ovarian cancer prognosis (NHS/NHSII): a cohort study. Lancet Oncol (2018) 19 (8):1107-16. doi: 10.1016/S1470-2045(18)30373-5

22. Wield AM, Walsh CS, Rimel BJ, Cass I, Karlan BY, Li AJ. Aspirin use correlates with survival in women with clear cell ovarian cancer. Gynecol Oncol Rep (2018) 25:78-81. doi: 10.1016/j.gore.2018.06.004

23. Dixon SC, Nagle CM, Wentzensen N, Trabert B, Beeghly-Fadiel A, Schildkraut JM, et al. Use of common analgesic medications and ovarian cancer survival: results from a pooled analysis in the Ovarian Cancer Association Consortium. Br J Cancer (2017) 116(9):1223-8. doi: 10.1038/ bjc. 2017.68

24. Verdoodt F, Kjaer SK, Dehlendorff C, Friis S. Aspirin use and ovarian cancer mortality in a Danish nationwide cohort study. Br J Cancer (2018) 118 (4):611-5. doi: 10.1038/bjc.2017.449

25. Gonzalez R, Gockley AA, Melamed A, Sugrue R, Clark RM, Del Carmen MG, et al. Multivariable analysis of association of beta-blocker use and survival in advanced ovarian cancer. Gynecol Oncol (2020) 157(3):700-5. doi: 10.1016/ j.ygyno.2020.03.012

26. Stroup DF, Berlin JA, Morton SC, Olkin I, Williamson GD, Rennie D, et al. Meta-analysis of observational studies in epidemiology: a proposal for reporting. Meta-analysis Of Observational Studies in Epidemiology (MOOSE) group. JAMA (2000) 283(15):2008-12. doi: 10.1001/ jama.283.15.2008

27. Higgins J, Green S. Cochrane Handbook for Systematic Reviews of Interventions Version 5.1.0. The Atrium Southern Gate Chichester PO19 8SQ, UK: John Wiley \& Sons Ltd (2011). Available at: www. cochranehandbook.org.

28. Wells GA, Shea B, O'Connell D, Peterson J, Welch V, Losos M, et al. The Newcastle-Ottawa Scale (NOS) for assessing the quality of nonrandomised studies in meta-analyses. (2010). Available at: http://www.ohri.ca/programs/ clinical_epidemiology/oxford.asp (Accessed on May 28, 2020).

29. Higgins JP, Thompson SG. Quantifying heterogeneity in a meta-analysis. Stat Med (2002) 21(11):1539-58. doi: 10.1002/sim.1186

30. Patsopoulos NA, Evangelou E, Ioannidis JP. Sensitivity of between-study heterogeneity in meta-analysis: proposed metrics and empirical evaluation. Int J Epidemiol (2008) 37(5):1148-57. doi: 10.1093/ije/dyn065

31. Egger M, Davey Smith G, Schneider M, Minder C. Bias in meta-analysis detected by a simple, graphical test. BMJ (1997) 315(7109):629-34. doi: 10.1136/bmj.315.7109.629

32. Drake JG, Becker JL. Aspirin-induced inhibition of ovarian tumor cell growth. Obstet Gynecol (2002) 100(4):677-82. doi: 10.1016/S0029-7844(02)02214-7

33. Uddin S, Ahmed M, Hussain A, Assad L, Al-Dayel F, Bavi P, et al. Cyclooxygenase-2 inhibition inhibits PI3K/AKT kinase activity in epithelial ovarian cancer. Int J Cancer (2010) 126(2):382-94. doi: 10.1002/ijc.24757

34. Cooke NM, Spillane CD, Sheils O, O’Leary J, Kenny D. Aspirin and P2Y12 inhibition attenuate platelet-induced ovarian cancer cell invasion. BMC Cancer (2015) 15:627. doi: 10.1186/s12885-015-1634-X

35. Huang Y, Lichtenberger LM, Taylor M, Bottsford-Miller JN, Haemmerle M, Wagner MJ, et al. Antitumor and Antiangiogenic Effects of Aspirin-PC in Ovarian Cancer. Mol Cancer Ther (2016) 15(12):2894-904. doi: 10.1158/15357163.MCT-16-0074

Conflict of Interest: The authors declare that the research was conducted in the absence of any commercial or financial relationships that could be construed as a potential conflict of interest.

Copyright (c) 2021 Man, Wang, Tan, Yang and Zhang. This is an open-access article distributed under the terms of the Creative Commons Attribution License (CC BY). The use, distribution or reproduction in other forums is permitted, provided the original author(s) and the copyright owner(s) are credited and that the original publication in this journal is cited, in accordance with accepted academic practice. No use, distribution or reproduction is permitted which does not comply with these terms. 